Mr Dejan Ivković, kapetan prve klase, dipl. inž. Vojna akademija Beograd

\section{KONCEPT SOFTVERSKOG RADARA}

UDC: $621.396 .96: 004.4$

Rezime:

U ovom radu analiziran je koncept softverskog radara. Zbog velike fleksibilnosti softverski radar ima mnoge prednosti u odnosu na konvencionalne radare. Takođe, održavanje softverskog radarskog sistema je mnogo jeftinije. Predstavljena je teorijska i tehnološka osnovica softverskog radara i opisana njegova arhitektura, kao i način organizacije njegove mreže. Ploča DSP (Digital Signal Processing) predstavlja centralni deo softverskog radara, pa je detaljno predstavljena njena uloga. Opisana je platforma quatro 6x i akviziciona kartica PCI-9812/10. Rezultat sprovedene tehno-ekonomske analize pokazuje da je za stvarnu implementaciju projektovanih softverskih modula radarskog prijemnika u konkretni konvencionalni radar potrebno izdvojiti oko 20000 USD, što je mnogo manje od cene modernih radarskih sistema.

Ključne reči: softverski radar, konvencionalni radar, DSP ploča, radarska mreža, akvizicija podataka.

\title{
SOFTWARE RADAR CONCEPT
}

Summary:

Software radar concept is described in this paper. Because of high level of flexibility software radar has many advantages in aspect to conventional radar. Also, service of the software radar system is much cheaper. Theoretical and technical basis of software radar is presented and its architecture is proposed. Organization method of the software radar network is specified. DSP (Digital, signal Processing) board is central part of the software radar and its role is described in details. Quatro 6x platform and PCI-9812/10 acquisition card are described. Result of the given techno-economical analysis approves that it is necessary to invest around $20000 \$$ and that is much less than the price of modern radar systems.

Key words: software radar, conventional radar, DSP board, radar network, data acquisition.

\section{Uvod}

S napretkom tehnike digitalne obrade signala i signal-procesorskih tehnologija, teorijski i praktično je razrađen koncept softverskog radija. Termin softverski radio prvi put je pomenut početkom poslednje decenije prošlog veka da bi se definisao radio čija je funkcionalnost obezbeđena preko softverskih i hardverskih komponenata. U takvoj realizaciji radija udeo softverskih komponenata je oko $80 \%$, a hardverskih oko $20 \%$. U stvari, realizacija softverskog radija sastoji se u tome da se deo hardvera klasičnog radija zameni signal-procesorskom platformom, na kojoj se softverski implementira deo funkcija radija. Mnoge aspekte dizajna $\mathrm{i}$ implementacije softverskih radio-sistema predstavio je Rid (Reed) 2002. godine [1]. Koncept softverskog radara predstavlja specifičnu primenu softverskog radija. Softverski radar prvi put se pominje krajem poslednje de- 
cenije dvadesetog veka, kao radarski uređaj čije su funkcije softverski definisane.

Softverski radar mora biti fleksibilan, reprogramabilan, da omogućava upravljanje različitim komunikacionim protokolima i rad na različitim frekvencijama, a da pri tome koristi istu hardversku platformu koja je pod softverskom kontrolom [2]. Prema tome, puko postojanje DSP ploče (Digital Signal Processor) u sastavu radara ne znači da je taj radar softverski.

Glavna karakteristika softverskog radara je njegova fleksibilnost. Jednostavnom izmenom, dopunom ili zamenom softvera, mogu se potpuno promeniti i unaprediti funkcije i karakteristike radara. Na ovaj način radarski uređaj je lako modernizovati, jer se primena najmodernijih tehnika obrade radarskih signala može veoma brzo implementirati bez velikih hardverskih promena.

Funkcije digitalnog radarskog sistema, koje su najčešće implementirane softverski, jesu obrada signala, generisanje talasnog oblika predajnog signala, kontrola rada antenskog sistema i sinhronizacija svih funkcionalnih celina sistema. Takođe, mora se obezbediti rad u realnom vremenu. Pošto se pri obradi signala obavljaju komplikovani matematički proračuni, neophodna je obrada na brzim digitalnim signal-procesorskim pločama.

Softverski radar pruža mnogo bolje mogućnosti prikazivanja podataka dobijenih na osnovu obrađenih signala i detekcije ciljeva. Kod konvencionalnih radara pokazivač je relativno skromnih mogućnosti i na njemu se, uglavnom, mogu prikazivati ciljevi u obliku osvetljenih tačaka, a daljina i uglovni položaj cilja mogu se samo grubo proceniti. Kod pokazivača softverskog radara praktično ne postoje granice. Svaki podatak do kojeg se došlo pri obradi radarskog signala može se veoma precizno prikazati na monitoru računara koji je u sastavu softverskog radara. To podrazumeva ispisivanje preciznih koordinata ciljeva koje može biti u obliku odgovarajućih tabela ili se pored svakog cilja ispisuju njegove osnovne koordinate. Moguća je selekcija i obeležavanje pripadnosti cilja, što je posebno bitno za radare koji se koriste u vojne svrhe, koji moraju da razlikuju sopstvene letilice od civilnih ili neprijateljskih letilica. Mnogo je lakše izvodljivo crtanje trajektorija selektovanih ciljeva i pridruživanje različitih simbola za različite klase ciljeva.

\section{Teorijska i tehnološka osnovica softverskog radara}

Opšta šema jednog softverskog radara prikazana je na slici 1 . Svaki blok čine modularne komponente koje su izabrane u skladu s namenom sistema [3].

Blok nazvan sintetizator talasnog oblika generiše odgovarajući predajni signal impulsne ili kontinualne prirode koji će modulisati hiperfrekventni nosilac. Ovaj blok softverskog radara je fleksibilan, što znači da se oblik predajnog signala može menjati tokom rada. Kod radara koji rade sa signalima u proširenom spektru, sintetizator talasnog oblika generiše predajni signal koji je kodiran po frekvenciji ili fazi, što doprinosi poboljšanju rezolucije po daljini. Dakle, ovakav sintetizator mora da obezbedi veliku širinu propusnog opsega (reda GHz) i visok stepen agilnosti frekvencije (kratak vremenski interval „skakanja“ s jedne na drugu predajnu frekvenciju, oko $100 \mathrm{~ns}$ ). 


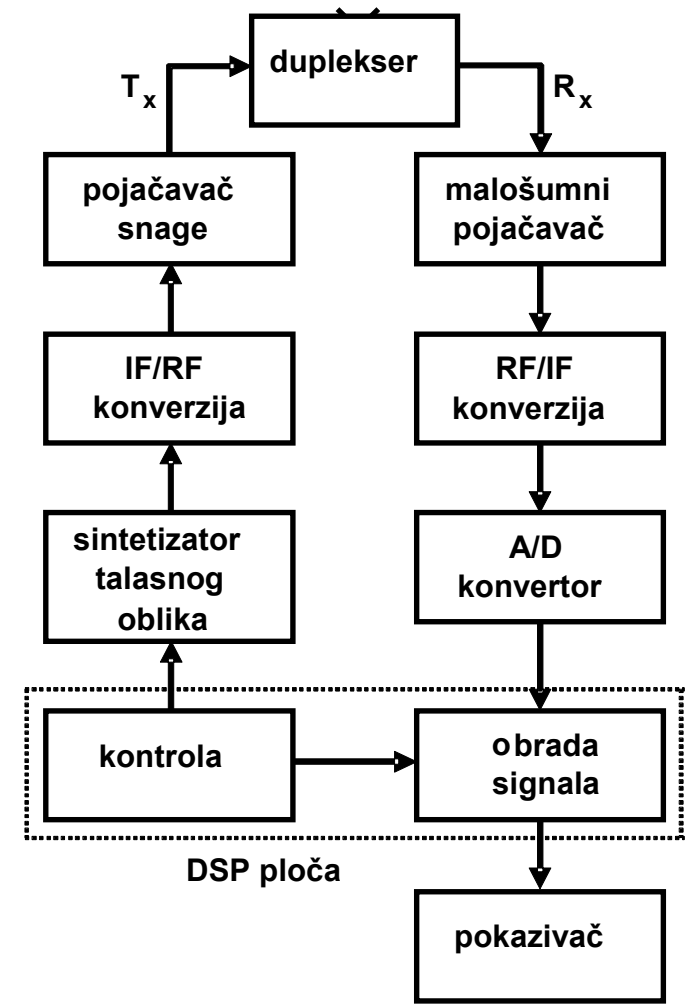

Sl. 1 - Softverski radarski sistem

Blok za IF/RF konverziju treba da translira spektar generisanog signala $u$ područje hiperfrekvencija reda gigaherca, što se najčešće realizuje preko višestepenog umnožavanja frekvencije signala kvarcnog oscilatora.

Visokofrekventni pojačavač snage treba da ima što veće pojačanje, ali i veoma mali faktor šuma, kako bi izobličenje predajnog talasnog oblika bilo manje. Kao visokofrekventni pojačavači mogu se koristiti klistroni, parametarski pojačavači, a najčešće cev sa putujućim talasom (Traveling Wave Tube - TWT) koja obezbeđuje pojačanja snage preko $50 \mathrm{~dB}$ sa faktorom šuma manjim od 2.

Blok-duplekser ustvari je antenska skretnica koja kod impulsnog radara usmerava elektromagnetnu energiju ka anteni, u intervalima predaje radarskog signala. U intervalima kada nema predaje radarskog signala, duplekser sve signale koji se nalaze na ulazu antenskog sistema propušta prema prijemnom kanalu.

Kao i kod konvencionalnog radara i ovde je prvi blok u prijemnoj grani malošumni pojačavač. Njegov naziv govori da je to pojačavač sa malim faktorom šuma, a poželjno je da ima što veće pojačanje.

Blok za RF/IF konverziju ima suprotnu funkciju od bloka za IF/RF konverziju. Naime, spektar prijemnog signala se iz područja hiperfrekvencija translira $u$ tzv. međufrekventni opseg, koji je obično reda nekoliko desetina megaherca radi lakše digitalne obrade signala. U okviru ovog bloka nalazi se sklop nazvan IQ-demodulator. U literaturi se sreće pod nazivom sinhroni detektor. Funkcija IQ-demodulatora je da razdvoji realnu i imaginarnu komponentu kompleksnog prijemnog radarskog signala i da na svom izlazu da informaciju o njegovoj fazi i amplitudi, koja će se iskoristiti za potiskivanje interferencije prisutnog klatera.

Analogno-digitalni (A/D) konvertor ima brojne primene u savremenim radarima, a naročito kod softverskih radara. $\mathrm{Na}$ primer, kod MTI radara (Moving-Target Indication), koji selektuju pokretne ciljeve, potreban je A/D konvertor sa frekvencijama odabiranja reda nekoliko megaherca, pa i većim. Ovde se signali na izlazu iz sinhronog detektora odabiraju brzinom koja ne sme da bude manja od širine propusnog opsega prijemnika, a za smeštanje digitalizovanih podataka potrebna je memorija sa kapacitetom reda gigabajta. Brzi $\mathrm{A} / \mathrm{D}$ konvertori potrebni su i kod radara za automatsko praćenje 
ciljeva, a i kod višesnopovskih radara koji do koordinata cilja dolaze preko aritmetičke interpolacije.

Kod softverskog radara, izlaz A/D konvertora je direktno spregnut s blokom za obradu signala koji zajedno sa blokom za kontrolu čini centralni deo softverskog radara, tj. DSP ploču (Digital Signal Processing), koja predstavlja centralnu kontrolnu jedinicu čitavog sistema. Što je najvažnije, obezbeđuje digitalnu obradu signala u realnom vremenu. Pored obrade signala DSP, ploča obavlja još jednu bitnu funkciju - obradu podataka.

Obrađene podatke treba konvertovati u pogodan oblik da bi se prikazali korisniku radarskog uređaja na odgovarajućem pokazivaču. Pokazivač softverskog radara najčešće je monitor računara, što govori o mnogo boljim mogućnostima prikazivanja dobijenih informacija o ciljevima i većoj preglednosti koja omogućuje lakše rukovanje sistemom. Na pokazivačima konvencionalnih radara postoje mnogo skromnije mogućnosti obeležavanja i markiranja ciljeva nego kod softverskog radara. Dakle, softverski radari imaju bolji kvalitet i kvantitet podataka koji se prikazuju na pokazivaču.

\section{Arhitektura softverskog radara}

Na slici 2 detaljnije je prikazana arhitektura softverskog radara [4], u kojoj se jasno uočavaju dve vrste komponenata: hardverske i softverske komponente.

Hardverske komponente na slici 2 uokvirene su isprekidanom linijom. One se ne razlikuju od odgovarajućih blokova kod konvencionalnih radara. U njih spadaju IF/RF konvertor, pojačavači, svi mikrotalasni elementi, antenski sistem sa ele- mentima za pozicioniranje antene, predajni usmereni sprežnik i koherentni digitalni prijemnik, koji u svom sastavu ima A/D konvertor i IQ-demodulator. Predajni usmereni sprežnik, zajedno sa koherentnim digitalnim prijemnikom čini posebnu prijemnu granu za proveru i podešavanje parametara radarskog prijemnika. Softverske komponente preuzele su funkcije digitalnih hardverskih komponenata $\mathrm{u}$ konvencionalnim radarima koje su obezbeđivale obradu signala, generisanje talasnog oblika predajnog signala, kontrolu rada antenskog sistema i memorisanje podataka. Da bi se sve pomenute funkcije odvijale u realnom vremenu, neophodna je veoma brza interna mreža kojom bi se uspostavila međusobna komunikacija između elemenata hardvera, računara sa DSP procesorom i elemenata za nadzor i kontrolu rada celokupnog sistema. U sistemu je potrebna dobra sinhronizacija rada svih njegovih elemenata. Pored standardnih načina sinhronizacije, ona se može obezbediti i preko DSP ploče.

Sekvencer predajnog talasnog oblika ima istu funkciju kao sintetizator talasnog oblika sa slike 1. Merenjem osnovnih parametara predajnog signala $u$ jednom bloku softverskog radara, kao što su frekvencija nosioca, trajanje predajnog impulsa i frekvencija ponavljanja impulsa, kontinualno se proverava kvalitet predajnog talasnog oblika.

Rad antenskog sistema kontroliše blok pod nazivom sekvencer pozicije antene. Ovaj blok kontroliše rad antenskog sistema, tako što meri frekvenciju obrtanja antene i, ako nije u dozvoljenim granicama odstupanja, automatski je podešava preko upravljačkih signala. Sekven- 


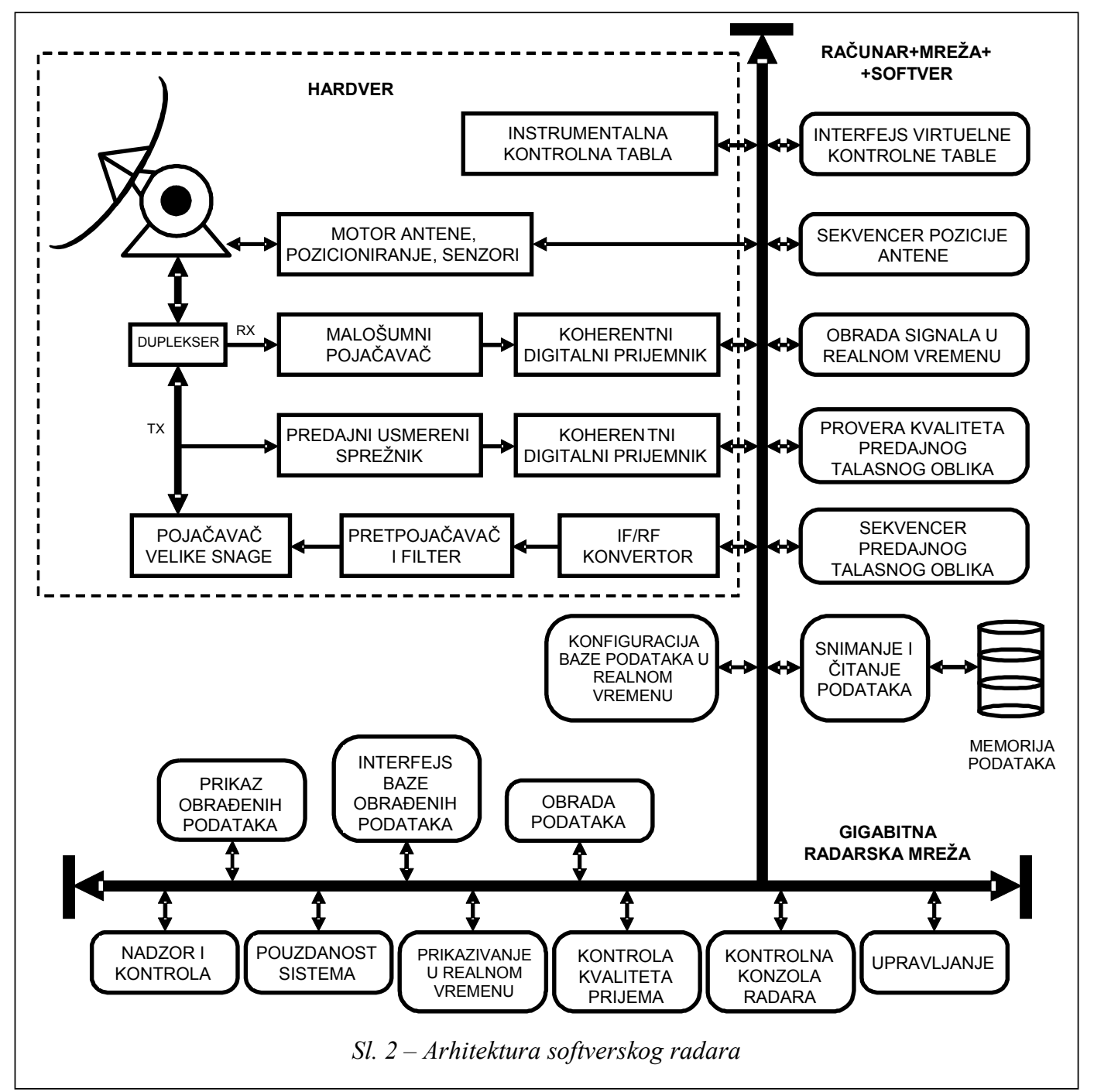

cer pozicije antene ima još jednu bitnu funkciju - generisanje uglovnih pozicija antene na početku svake periode predajnog signala. Kada je uglovna pozicija antene po azimutu $0^{\circ}$, antena je napravila jedan pun obrtaj, a svaki takav trenutak se precizno meri da bi se izbegla desinhronizacija pri konfiguraciji baze podataka u realnom vremenu. Baza podataka ima matrični oblik. U njoj vektori kolone odgovaraju rednom broju predajnog im- pulsa, a vektori vrste rednom broju ćelije daljine. Memorija podataka puni se i prazni preko bloka za snimanje i čitanje podataka.

U bloku za obradu signala na slici 2, koji je realizovan pomoću DSP ploče, primenom odgovarajućih algoritama vrši se digitalna obrada u realnom vremenu. Koherentni digitalni prijemnik pretvara analogni prijemni signal RX u digitalni oblik tako da faza signala bude stabilna. 
Digitalizovani prijemni signal RX sadrži povratnu informaciju o posmatranom radarskom cilju. U bloku za obradu signala izdvajaju se informacije o cilju po daljini, Doplerovoj frekvenciji i vremenu. Prijemni signali koji potiču od jednog predajnog impulsa moraju biti obrađeni u realnom vremenu, odnosno u toku jedne periode ponavljanja impulsa.

Na DSP ploči realizovan je i blok za obradu podataka. U njemu se određuju koordinate detektovanih ciljeva, a to su kod dvodimenzionalnih radara najčešće daljina i azimut. Trodimenzionalni radari određuju i elevaciju cilja. Bitan podatak je brzina cilja, pa se u bloku za obradu podataka detektovanim ciljevima pridružuje informacija o njihovoj brzini. $\mathrm{Na}$ osnovu obrađenih podataka formira se njihova baza, koja se preko odgovarajućeg interfejsa prenosi do bloka za prikazivanje obrađenih podataka na pokazivaču softverskog radara. Podaci se moraju prikazati u realnom vremenu, što važi i za obradu signala. Kod softverskog radara postoji memorija podataka, pa se, u zavisnosti od njene veličine, na pokazivaču mogu reprodukovati kraće ili duže ponovljene sekvence radarske slike.

Sistem kontrole i upravljanja softverskog radara čine sledeći elementi: kontrolna konzola radara, virtuelna kontrolna tabla, kola za nadzor i kontrolu, kola za merenje pouzdanosti sistema, blok za kontrolu kvaliteta prijema i blok za upravljanje.

Kontrolna konzola objedinjuje sve ostale elemente sistema za kontrolu i upravljanje, a upravlja se preko komandi koje su na njoj instalirane. Na virtuelnoj kontrolnoj tabli instalirani su pokazivači stanja pojedinih funkcionalnih blokova softverskog radara, koja predstavljaju izlazne signale kola za nadzor i kontrolu. Najčešći parametri koji podležu kontroli jesu: snaga predajnog signala, frekvencija nosioca predajnog signala, pravilnost rada bloka za obradu signala, pravilnost rada bloka za obradu podataka, frekvencija obrtanja antene, nivelacija antene, vrednost svih potrebnih napona napajanja potrebnih za rad hardverskih komponenata i odnos signal - šum na ulazu u prijemnik radara koji određuje blok za kontrolu kvaliteta prijema. Blok za upravljanje generiše upravljačke signale za koje postoji zahtev sa kontrolne konzole i preko interne mreže ih prosleđuje ka bloku softverskog radara na kojem treba izvršiti zahtevanu akciju.

\section{Radarska mreža}

Ako se softverski radar (slika 2) poveže u mrežu sa drugim radarima, onda interna mreža prerasta u tzv. gigabitnu radarsku mrežu, čija je struktura prikazana na slici 3. Da bi se uspostavio visok stepen paralelizma procesa, kao što su obrada signala, obrada podataka i nadzor radarskog sistema, neophodno je da radarska mreža bude višekanalna (Multicast Network).

Tipičan skup kanala kod softverskog radarskog sistema čine kanal kontrole, kanal podataka, kanal stanja i kanal preko kojeg se vrše izmene postojećih programa i unošenje novih. Kanali mogu biti trajni ili privremeni, što zavisi od zahteva koji se postavljaju pred softverski radarski sistem. 


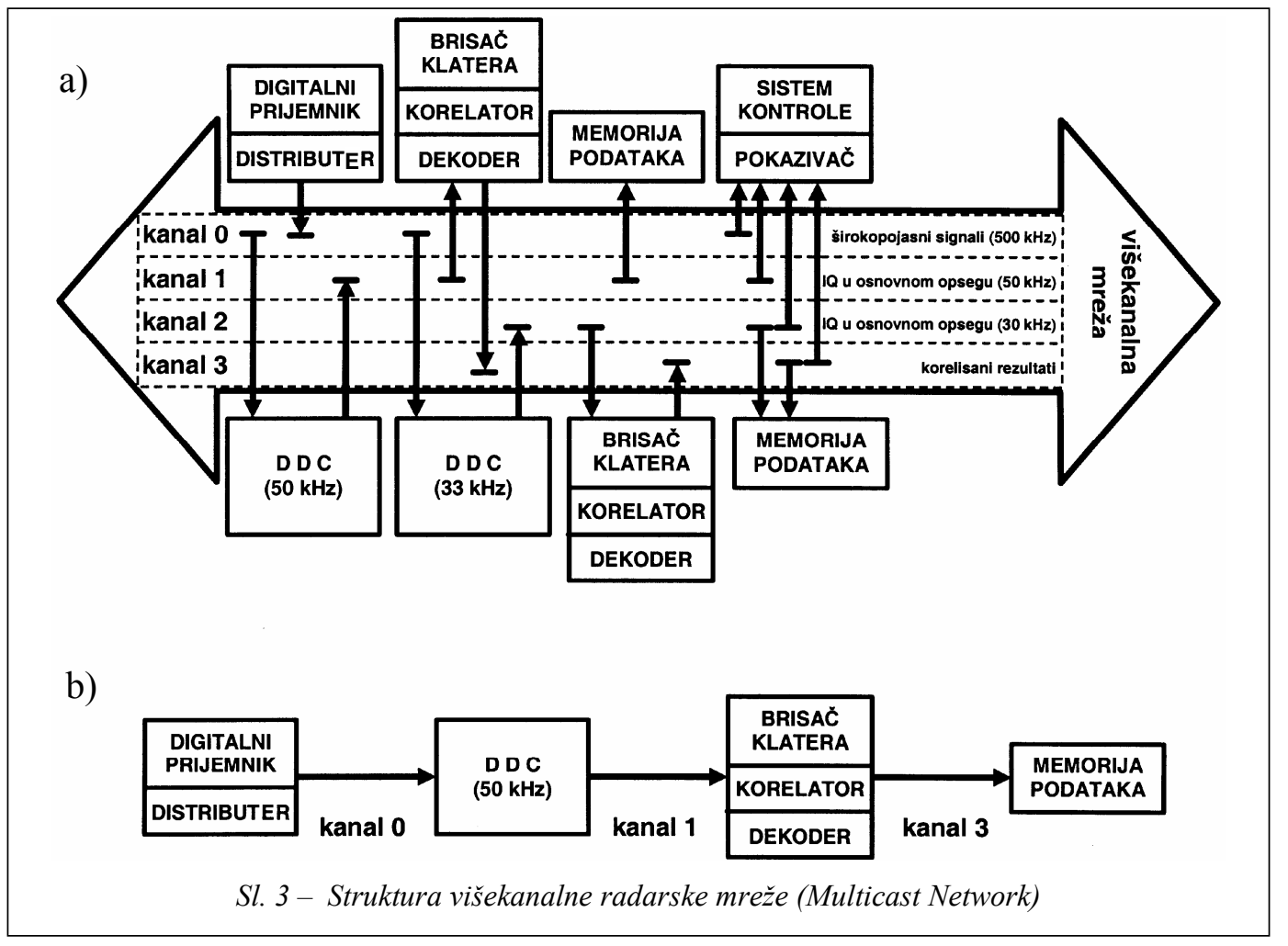

Na slici 3a) prikazan je primer organizacije kanala u mreži softverskih radara [4]. U ovom primeru, na kanalu podataka nalaze se prijemni podaci (kanal 0). Podaci sa ovog kanala su istovremeno dostupni različitim blokovima softverskog radarskog sistema koji mere temperaturu šuma sistema, transliraju spektar signala, filtriraju podatke i prikazuju dobijene rezultate. Signali na izlazu koherentnog digitalnog prijemnika formatiraju se u bloku pod nazivom distributor. Formatirani signali se preko kanala 0 prenose do bloka sa oznakom DDC (Digital Downconverter) koji translira spektar signala oko određene centralne frekvencije. U ovom primeru postoje dva takva konvertora sa centralnim frekvencijama 33 i $50 \mathrm{kHz}$. Signal na izlazu
DDC-a sa centralnom frekvencijom 50 $\mathrm{kHz}$ prenosi se u kanal 1, a na izlazu iz DDC-a sa centralnom frekvencijom 33 kHz u kanal 2.

Podaci iz kanala 1 i kanala 2 memorišu se odvojeno u dve različite memorije podataka i dalje se obrađuju u različitim blokovima. Obrađeni podaci prenose se u kanal 3, odakle mogu biti prosleđeni u blok za memorisanje ili se direktno prenose do bloka za prikazivanje rezultata obrade. Jedan lanac blokova za obradu signala prikazan je na slici 3b). Konfiguracija ovog lanca može biti promenljiva, pa se vrlo brzo može modifikovati kao odgovor na promenjene zahteve u obradi signala.

Računari koji funkcionišu u sklopu softverskog radarskog sistema imaju ograničene kapacitete. Međutim, kada se 
povežu preko radarske višekanalne mreže postaju mnogo efikasniji i u najsloženijim radarskim aplikacijama. Svi elementi povezani u mrežu mogu da komuniciraju jedni s drugima.

Upotrebom višekanalne radarske mreže podstiče se velika modularnost blokova za obradu podataka, što ostvaruje glavni cilj - visoki nivo paralelizma različitih procesa koji se odvijaju u softverskom radarskom sistemu.

\section{Uloga DSP ploče}

Pred DSP ploču postavlja se zahtev da obezbedi obradu signala $u$ realnom vremenu. U digitalnoj obradi signala najčešće operacije biće Furieova transformacija (FFT), konvolucija (korelacija) i sinteza FIR filtera. U sva tri slučaja, funkcija koju treba da obavi digitalno kolo ima oblik:

$$
y=\sum_{i=1}^{n} x_{i} \cdot c_{i}
$$

Po svojoj arhitekturi, digitalni procesori signala (DSP) specijalizovani su za izračunavanje sume proizvoda, kao u jednačini (1). Takođe, omogućen je simultani pristup odvojenim blokovima memorije radi bržeg pristupa podacima. Izvršavanje instrukcija pažljivo je planirano i vrši se po principu pipelininga, čime je rad procesora znatno ubrzan. Najvažniji zadaci koje DSP obavlja u radarskom prijemniku jesu procena Doplerove frekvencije i CFAR procesiranje. Prema [5] broj instrukcija za implementaciju FIR filtera, koji obavlja Doplerovu obra$\mathrm{du}, \mathrm{N}_{\mathrm{i}}$, jednak je broju reflektovanih im- pulsa od cilja u toku jednog prebrisavanja antene, N, koji zavisi od frekvencije obrtanja antene, $f_{s}$, frekvencije ponavljanja impulsa, $f_{r}$, i širine dijagrama zračenja antene, $\theta_{3 \mathrm{~dB}}$, prema jednačini [6]:

$$
N_{i}=N=\frac{f_{r} q_{3 d B}}{2 p f_{s}}
$$

Tome treba dodati još desetak pomoćnih naredbi. Realizacija CFAR procesora zahteva dve instrukcije po svakoj ćeliji i, kao u prethodnom slučaju, još desetak pomoćnih naredbi. Prema tome, zahtevana brzina procesora može se izračunati na osnovu sledeće jednačine [5]:

$$
R_{i}=\frac{N+10+2 \cdot 2 n+10}{\tau}=\frac{N+4 n+20}{\tau}
$$

gde je $2 n$ broj ćelija CFAR procesora, a $\tau$ trajanje predajnog impulsa. Na primer, kod radara ŽIRAFA broj reflektovanih impulsa od cilja u toku jednog prebrisavanja maksimalno iznosi $\mathrm{N}=20$, a broj ćelija CFAR procesora je $2 n=8$. Kada se proračuna zahtevana brzina procesora po jednačini (3) dobija se vrednost oko 10 MIPS (Mega Instructions Per Second). Za postojeće digitalne procesore signala ova brzina procesiranja ne predstavlja problem.

Prelazak sa analogne na digitalnu obradu signala može se izvršiti na više mesta u toku procesiranja prijemnog signala. Signal se, najčešće, digitalizuje na izlazu iz IQ-demodulatora. Specifičnost i zahtevnost obrade signala u radarskoj tehnici iziskuju vrlo pažljiv izbor hardverskih platformi za realizaciju funkcionalnih blokova softverskog radarskog prijemnika. 
Za realizaciju projektovanih softverskih modula neophodne su sledeće hardverske komponente: akviziciona kartica, DSP platforma, host računar i laptop.

Akviziciona kartica koja bi zadovoljila potrebne zahteve za primenu u softverskom radaru je PCI-9812/10 (slika 4), koju proizvodi firma ADLINK Technology Inc. Kartica se bazira na 32-bitnoj PCI BUS arhitekturi i poseduje četiri 12--bitna A/D konvertora sa maksimalnom frekvencijom odabiranja od $20 \mathrm{MHz}$ po kanalu. Najčešće se primenjuje u radu sa DSP pločama i u aplikacijama u kojima se izvodi brza Furieova transformacija, digitalno filtriranje ili obrada slike. Na kartici postoji 64KB FIFO memorije. Opseg ulaznih napona može biti od -5 do $+5 \mathrm{~V}$, ili -1 do $+1 \mathrm{~V}$.

Platforma DSP koja bi mogla da odgovori na sve zahteve obrade signala u realnom vremenu je Quatro 6x, koju proiz-

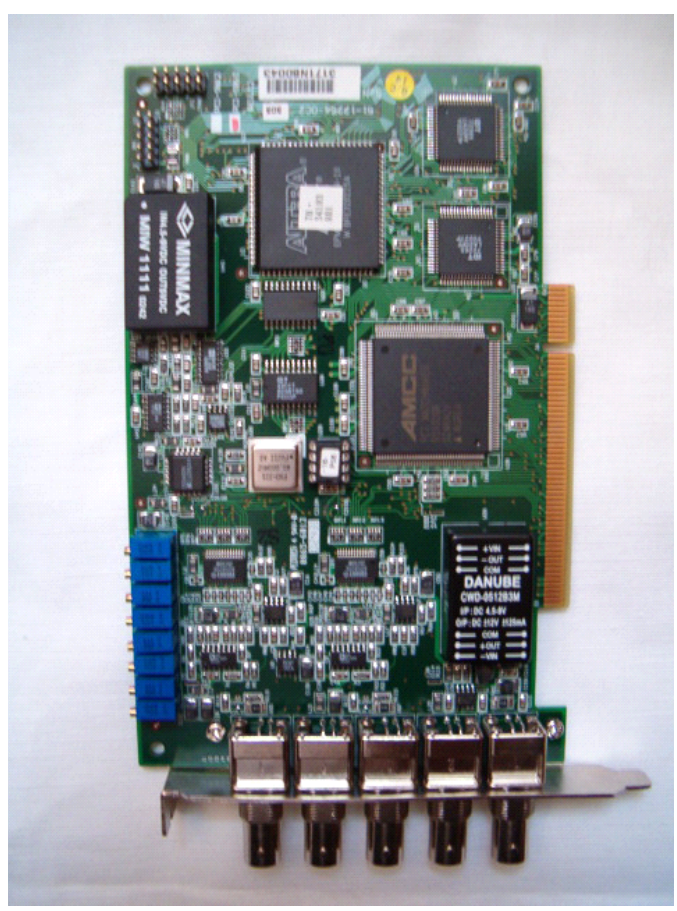

Sl. 4 - Kartica PCI-9812/10 vodi firma Innovative Integration. Na njoj su integrisana četiri TMS320C6201 DSP procesora na $200 \mathrm{MHz}$ (slika 5). Ova platforma je idealna za upotrebu kod velikog broja računski zahtevnih aplikacija. Brzina izvođenja operacija je 1,3 GFLOPS-a.

Svaki procesor ima veliki broj periferija na čipu, uključujući dva 32-bitna brojača, $64 \mathrm{~KB}$ internog PROGRAM RAM-a (IPRAM), 64 KB internog RAMa podataka (IDRAM), $16 \mathrm{MB}$ eksternog RAM-a (SDRAM) i četiri DMA kanala. Sva četiri procesora su međusobno povezana pomoću brzih FIFO linkova, koji su kompatibilni sa procesorskim DMA kontrolerima, što obezbeđuje potreban kvalitet razmene podataka između procesora. Tri DSP procesora mogu da komuniciraju sa eksternim hardverom pomoću zasebnih 16-bitnih FIFOPort interfejsa. Serijski portovi svakog DSP procesora platforme Quatro 6x izvedeni su na konektore za povezivanje sa eksternim hardverom. Akviziciona kartica i platforma Quatro 6x bile bi smeštene u kućište jedanog tzv. host računara. Minimalna RAM memorija je 512 $\mathrm{MB}$, a brzina procesora oko $2 \mathrm{GHz}$.

Ako se želi da posada, zbog povećanja mera bezbednosti, upravlja radom radara van njegove kabine, biće potreban laptop računar, koji će biti u mreži sa host računarom. Komunikacija između njih može se ostvariti žičnim ili radio-putem.

Kada se saberu cene navedenih harverskih komponenti, dobije se ukupan iznos od oko 20000 \$. Imajući u vidu da najnoviji radarski sistemi koštaju od nekoliko miliona do nekoliko desetina miliona američkih dolara, modifikacija konvencionalnih vojnih i civilnih radara starije generacije, na bazi softverski definisanog radara, bila bi veoma isplativa. 


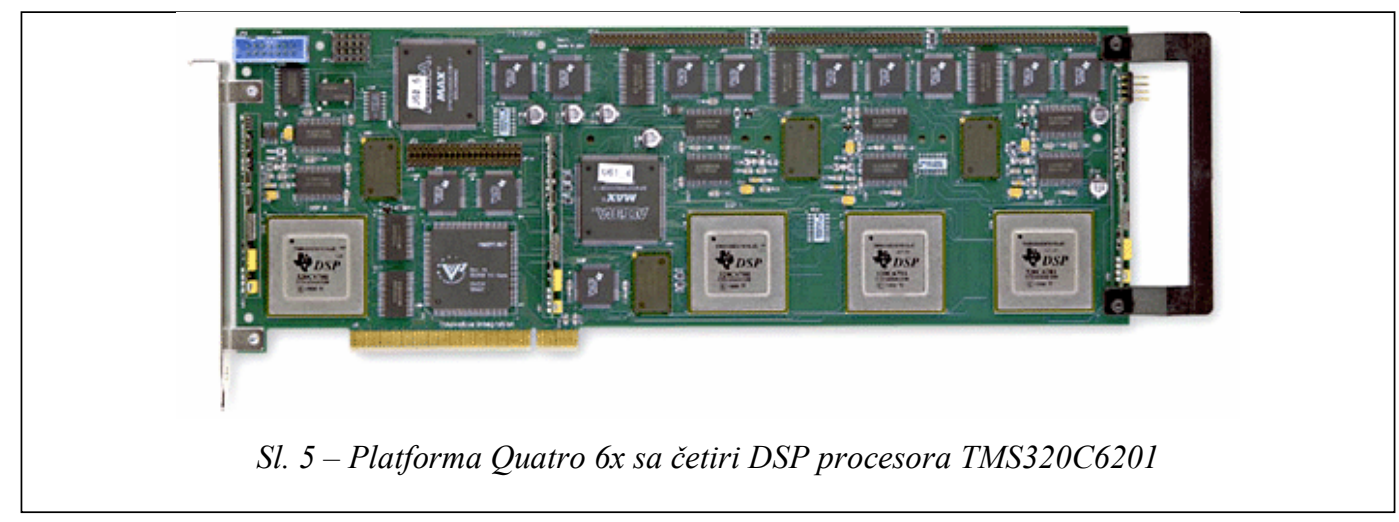

\section{Zaključak}

Softverski radar je fleksibilan i reprogramabilan uređaj čije su funkcije softverski definisane. Projektovanjem softverskog modela nekog konvencionalnog radara dobija se sistem čije je održavanje mnogo ekonomičnije. Uvođenje samo softverskog radarskog prijemnika omogućava rešenje problema s nabavkom većeg broja rezervnih delova prijemnika konvencionalnog radara, jer oni više nisu potrebni. Uz to, komponente softverski definisanog radara mnogo su jeftinije od onih u postojećim sistemima, pa bi održavanje softverskog radarskog prijemnika bilo neuporedivo jeftinije od održavanja postojećih sistema konvencionalnih radara. Rešenja koja proističu iz ove analize primene koncepta softverskog radara mogla bi da se iskoriste za modifikaciju konvencionalnih radara, kako u vojnoj, tako i $\mathrm{u}$ civilnoj upotrebi. Primenom koncepta softverskog radara mogu se unaprediti karakteristike i povećati fleksibilnost konvencionalnih radara, kao i implementirati potpuno nove funkcije koje znatno unapeđuju njegove performanse. Osim toga, ovaj koncept otežava rad sistemima ELINT (Electronic Intelligence), što se ogleda u činjenici da softverski radar ima mogućnost jednostavne promene talasnog oblika predajnog signala, kao i njegovih ostalih parametara.

Za stvarnu implementaciju projektovanih softverskih modula radarskog prijemnika u konkretni konvencionalni radar potrebno je izdvojiti oko 20000 \$. U ovu sumu uključene su samo cene potrebnih hardverskih komponenata, dok cena intelektualnog rada nije. Imajući u vidu da najnoviji radarski sistemi koštaju od nekoliko miliona do nekoliko desetina miliona američkih dolara, modifikacija konvencionalnih vojnih i civilnih radara starije generacije, na bazi softverski definisanog radara, bila bi veoma isplativa.

Literatura:

[1] Reed, J. H.: Software Radio, Comunications Enginering and Emerging Technologies, Prentice-Hall PTR, 2002.

[2] Grydeland, T.: Interferometric and high time-resolution observations of Naturally Enhanced Ion-Acoustic Echoes at the EISAT Svalbard Radar: Software radar and Incoherent Scattering, Doctor Scientiarum Dissertation, Faculty of Science Department of Pfysics, University of Tromso, 2003.

[3] Derham, T.: Low Cos Open Architecture Radar System, University College, London, England, 2000.

[4] Grydeland, T.: Software radar signal processing, Annales Geophysicale, 2004.

[5] Popović, M.: Digitalna obrada signala, Nauka, Beograd, 1996.

[6] Schleher, D. C.: MTI and Pulsed Doppler Radar, Artech House, USA Norwood, 1991. 